perifèria

Número 15, diciembre 2011

www.periferia.name

\title{
Seminario: Simbolismo y Ritual. A modo de introducción.
}

\begin{abstract}
"Desde la esencia del preguntar se vuelve claro lo que el diálogo platónico pretende demostrar en su realización fáctica. El que quiera pensar tiene que preguntarse".
\end{abstract}

(H. G. Gadamer, Verdad y Método)

\section{El Seminario}

El simbolismo y el ritual es una de las esferas de interés más importantes y distintivas de la antropología sociocultural. Si bien en sus inicios la disciplina se ocupó de aquel difuso ámbito denominado religión, paulatinamente el análisis del simbolismo y el ritual se extendió a las más diversas esferas de la vida social, ampliando así su utilidad analítica a ámbitos comprendidos como extra-religiosos. En el fondo, era esta la intención del último Durkheim, fascinado por la efervescencia de las ceremonias generadas en sociedad y hondamente intrigado por los mecanismos que activaban tales fenómenos. Hoy en día, es innegable que el estudio de los fenómenos simbólicos y rituales constituye un área absolutamente clave para comprender la diversidad cultural.

Pese a la relevancia de este ámbito de estudio, un grupo de estudiantes de postgrado del Departamento de Antropología Social y Cultural de la Universidad Autónoma de Barcelona tuvimos la necesidad de una instancia académica que nos permitiera discutir y desarrollar esta línea de trabajo específica. Si bien la esfera simbólico ritual es abordada por diversas/os académicas/os del Departamento en relación con sus propias temáticas de investigación, considerábamos extremadamente necesario desarrollar un espacio de reflexión conjunta sobre esta dimensión. Una suerte de alegre fascinación por este ámbito, acompañada de un 


\section{perifèria}

Número 15, diciembre 2011

www.periferia.name

genuino interés por obtener importantes beneficios para el desarrollo de nuestros propios temas de investigación en curso, fueron los precedentes perfectos para crear una instancia al respecto.

Después de largas y encendidas conversaciones, endulzadas con tabaco y café, a comienzos del año académico 2010-11 surgió la idea de crear un seminario enfocado en la discusión de lecturas clave sobre simbolismo y ritual. Este seminario tenía por objetivo principal generar una instancia entre los/as estudiantes de postgrado que propiciara la lectura, análisis y discusión atenta de textos clásicos sobre simbolismo y ritual desde la perspectiva de la antropología social y cultural. Siempre bajo el presupuesto de que los textos clásicos son un material abierto y vivo, especialmente idóneo para suscitar preguntas e interpretaciones que continúan vertebrando a la disciplina. Esta iniciativa contó desde sus inicios con el apoyo del Departamento, especialmente de la profesora Virginia Fons y el profesor Dan Rodríguez.

La dinámica de trabajo establecida en del seminario se basó en la lectura sistemática y la discusión de textos previamente definidos. En una primera etapa el seminario estuvo enfocado específicamente en el estudio de autores clásicos de la antropología religiosa y ritual, desarrollada entre los meses de octubre y diciembre de 2010. Dado el éxito de esta primera instancia, decidimos desarrollar una segunda etapa del seminario, pero esta vez escogimos centrarnos específicamente en la perspectiva hermenéutica presente en este ámbito de estudios, llevándola a cabo entre los meses de enero y febrero de 2011. Sumando ambas etapas, se realizaron un total de 16 sesiones semanales desarrolladas normalmente durante todas las mañanas de los días jueves.

Cada sesión tuvo como foco la discusión de un texto específico, a partir del calendario previamente definido por los integrantes y donde cada uno pudo proponer los textos de su interés en base a sus propias investigaciones. Las sesiones se organizaron de la siguiente manera: todos los participantes realizaban una lectura atenta del texto respectivo, pero en cada sesión un integrante en concreto debía realizar una lectura más detallada del texto y, en lo posible, también entregaba un resumen o guión de los presupuestos básicos del mismo, las ideas 


\section{perifèria}

Número 15, diciembre 2011

www.periferia.name

principales y los puntos problemáticos, para luego exponerlos en la sesión respectiva. En función de esta información básica y la lectura personal de los textos, se daba paso a la discusión por parte de todos los integrantes.

Si bien la organización y sistematicidad del trabajo fueron vitales para que nuestro proyecto llegara a buen puerto, la verdadera esencia y motor de esta iniciativa nace de insaciables inquietudes personales, incontables conversaciones de pasillo y largas discusiones con amigos y profesores. En el fondo, todo el desarrollo del seminario y la culminación en los escritos que presentaremos a continuación, no hubiese sido ni siquiera pensable sin la siempre presente necesidad de comprender cultivada por cada uno de sus integrantes, celebrada ritualmente en el seminario. Se trataba, sobre todas las cosas, de una instancia abierta a la pregunta y el diálogo. Este fue el espíritu que siempre inundó nuestras exquisitas reuniones. Cada mañana de jueves, no sólo se reunía un grupo de amigos y compañeros a exponer y resumir los aspectos más importantes de algún texto magistral, sino que la fase más importante y que le otorgaba el sentido último a esta actividad acontecía cuando cada uno era interpelado de manera concreta por los textos y, seguidamente, ensayaba un diálogo abierto con sus pares. Era en este escenario donde emergían incontables preguntas y pocas respuestas, aunque no eran estas últimas las que más importaban. Finalmente, era la deliciosa sensación que esta actividad nos brindaba la que se convirtió en el fundamento de la iniciativa.

\section{Los artículos}

A pesar de que el seminario estuvo enfocado básicamente en la presentación, análisis y discusión de textos considerados clave, focalizamos nuestra experiencia dentro del desarrollo de las propias investigaciones que cada uno de los integrantes del seminario ha venido realizando. Del mar de preguntas y reflexiones que esta actividad sembró, propusimos que cada uno escogiera alguna problemática especialmente relevante según su interés y posteriormente darle el formato de artículo científico para publicarlos conjuntamente. Para ello, la revista Periferia era la plataforma más idónea para llevar a cabo esta publicación, para lo cual contamos con el apoyo del Comité Editorial desde el inicio. De esta forma, el dossier 


\section{perifèria}

Número 15, diciembre 2011

www.periferia.name

compuesto por tres trabajos de investigación que presentamos a continuación es el fruto concreto desarrollado por algunos de los integrantes del seminario y representa la culminación del mismo.

El primer trabajo presentado es de Wilson Muñoz, donde se presenta una revisión y discusión de las perspectivas teórico-metodológicas utilizadas para abordar el fenómeno religioso del pentecostalismo evangélico en América Latina; destacando la relevancia que tiene el análisis del fenómeno específicamente ritual, paradójicamente olvidado por la antropología y por los estudios sobre el pentecostalismo latinoamericano en general. Su propuesta aboga por volver nuestra mirada hacia este fenómeno central, bajo una perspectiva teórica acorde con su naturaleza comunicacional.

El segundo trabajo presentado es de Javier Mercado, quien nos muestra los primeros avances de una investigación centrada en el análisis del fenómeno de los Bailes Religiosos en la zona del norte de Chile. A modo de propuesta, se sugiere la relevancia que ha tenido esta práctica ritual en los procesos de configuración histórica de las identidades de clase y nacionales en esta zona del norte de Chile.

El último trabajo, de Marté Sánchez, es una interesante reflexión acerca de los supuestos teoréticos de la figura del testimonio y sus implicaciones en las investigaciones llevadas a cabo sobre el fenómeno de la memoria y de la justicia, muy en boga en la actualidad. El autor se pregunta por qué algunos investigadores sociales han hecho hincapié en determinados testimonios en desmedro de otros, restándole con ello complejidad al tema de estudio.

Esperamos que los trabajos aquí presentados reflejen parte de las discusiones centrales abordadas a partir del seminario, a partir del análisis de casos concretos. Pero además, queremos que sean un aporte a la discusión del fenómeno del simbolismo y el ritual, y que en lo posible incentiven también a otros estudiantes y profesores a llevar a cabo iniciativas como esta, pues son estas empresas las que finalmente permiten hacer Universidad.

Javier Mercado y Wilson Muñoz 